\title{
Reflection on Modern Fashion
}

\author{
Lingfen $\mathrm{Li}^{1{ }^{1 *}}$ \\ ${ }^{1}$ School of Design Art, Xiamen University of Technology, Xiamen, Fujian, China \\ "Corresponding author. Email: 751257112@qq.com
}

\begin{abstract}
Based on the background of modern fashion, this paper explores the development law of fashion from the perspective of culture and economy through the phenomena of fashion in different periods. It also discusses the relationship between the emergence and development of fashion as a social and cultural symbol and human's aesthetic consciousness, religious belief, moral and ethical concepts, as well as social politics, economy, culture and art from three aspects, namely "fashion connotation", "fashion and current problems" and "reflection on modern fashion". This paper summarizes the basic forms of fashion under different social ideologies, and makes an in-depth analysis of modern fashion phenomenon, and puts forward some opinions on the future development direction of fashion.
\end{abstract}

\section{Keywords: fashion, current problems, fashion industry, sustainable fashion}

\section{INTRODUCTION}

The word "fashion" suddenly appeared in the Chinese people's vision in the early 1980s after the reform and opening up. With the reform and opening up, the life styles of Europe, America, Japan, especially Hong Kong and Taiwan flooded into people's life through the media, such as bell-bottoms, jeans, suits, pop music, disco... Fashion has kicked off in China with a new look and is spreading rapidly among the younger generation, taking hundreds of millions of Chinese out of their blue-grey wardrobe and ushering in a society of many shapes and sizes. It was in the early 1990s that fashion really entered the life field of the public and began to be popular, when the results of reform and opening up began to show, and people became richer and richer, and they began to regard consumption as the pleasure of life. Although no one used "fashion" to describe their own life then, with the emergence of all kinds of fashion magazines aiming at recommending international fashion trends and lifestyles and some fashion pioneers eager to try, the era of fashion in mainland China came quietly. Subsequently, a series of chain reactions of the rapid economic development, the intervention of the Internet and the success of the WTO negotiations, created a huge flood of Chinese fashion, and the trend of internationalization is irreversible. The world's major brands have entered China, Pierre Cardin, Chanel, LV, Mercedes... The rapid development of the luxury industry has brought a brand new fashion lifestyle to the Chinese mainland, and the fashion industry has begun to take off. Since the beginning of the new millennium, the whole fashion industry has rapidly integrated with the international standards. "Fashion" stimulates people's senses with the help of all kinds of media, and the surging temptation of fashion affects and changes people's lives everywhere. In just a few decades, modern "fashion" has changed Chinese people's life concept and lifestyle like a whirlwind, and has become one of the most frequently used words. The mystery hidden behind the great magic of fashion and its development direction is worthy of deliberation and reflection.

\section{THE CONNOTATION OF FASHION}

\section{A. The concept of fashion}

From the perspective of its meaning, fashion is the social advocacy in a certain period, and $\mathrm{Ci}$ Hai's interpretation of fashion is "a spreading phenomenon of appearance behavior pattern. For example, novelty in dress, language, literature, religion, etc. tends to be quickly adopted and imitated by a large number of people and spreads widely. They express people's love and appreciation for beauty. Or sometimes people just vent personal inner suppressed emotions in this way. It falls under the category of cultural patterns of human behavior."

In terms of modern fashion characteristics, the word "fashion" comes from the West, which also refers to the styles in vogue. Since the costume style of the high society in the Renaissance, fashion started to be popular with "clothing culture" as the carrier and gradually became an important part of people's life. With the change of society, the development of economy and the acceleration of commercial civilization, the connotation and extension of fashion are constantly expanding, extending from the field of clothing to all aspects of life. Although fashion is more reflected in the material forms of clothing and its extended consumer goods, its 
essence is the representation of people's spiritual demand.

\section{B. Characteristics of fashion}

Fashion can be understood as a social fashion in a specific period of time. In a certain period of time, the life style of a few people is respected and imitated by the public as a kind of classics at present, forming a trend, which is fashion. Fashion is an act of imitation. As a socialized person, in order to survive in nature, a person must first be accepted and recognized by their group. On this premise, they also try to prove their own uniqueness to attract the attention of the group. People's psychology of conformity and psychology of differentiation provide a broad space for the emergence and spread of fashion. In the pursuit of fashion, people complete the confirmation of their individual social identity. Fashion begins with the imitation of a few people by the public, but ends and continues to be updated in the pursuit of individual differentiation. It is the conformity and separation of people that give fashion the power to move forward.

As a confirmation of human identity, fashion has been branded with the brand of class since the day it came into being. In the traditional society, people's survival is based on the hierarchical society with traditional belief as the axis, and under certain social morality and ethics system, fashion interprets the prevailing social practices of "classifying people into different hierarchies". For example, since the establishment of the etiquette system mainly represented by the yi (the upper outer garment worn by ancient Chinese) and chang (the bottom worn by ancient Chinese, with its shape like the long skirt today) by the ancient emperors to lead their people by example and thus govern the domestic and national society orderly, the costume system as a manifestation of social hierarchy, has been running through the whole history of ancient Chinese costume. With different standards of dress etiquette for different levels, and many restrictions on the clothes choice of common people, the dress fashion in the past reflected the maintenance of the regime and social class division to a large extent. In modern society, since the political power relationship in fashion has been deconstructed, there are no longer hierarchical boundaries in people's fashion expression. However, the seemingly disintegrating social hierarchy has been reinterpreted by fashion under the social framework of equality and freedom. The stylization, diversification and personalization of fashion have become new markers of different social classes under the modern democratic context. For the most part, fashion has its roots in the upper echelons of society. But when the lower classes imitate and follow the fashion, it becomes a thing of the past, and the wealthy begin to create and pursue new fashions to distinguish themselves from the lower classes. As Simmel said,
"Fashion is the product of class divisions..." In the direction and pursuit of fashion, different classes have found their own positions and values. People all try to adjust or change their identity through the pursuit of fashion to narrow the gap with their desired social class.

As the social avocation of a specific period, fashion has a strong timeliness. From the beginning, it spreads and then declines and disappears within a certain time. Finally, it is replaced by a new trend, presenting its periodic changes. From the perspective of the history of human development, fashion is the expression of the times. Each round of fashion marks a moment in history and reflects the lifestyle and aesthetic trend of people at different historical moments. In the course of historical changes, the costumes that reflect the fashion of the times, especially, show the changeable modality. In the open Tang Dynasty, fashion reflected romantic openness, fantastic and various appearance and magnanimity. Under the influence of Cheng and Zhu's Neo-Confucianism in Song Dynasty, the fashion reflected the plain, conservative and fresh look. During the Cultural Revolution, when "The Chinese people are full of high aspirations, and they prefer military uniform than gay feminine attire", military uniforms became the clothes pursued by the youth of the age, and the clothes reflected the consistency of the revolution. Today, after the reform and opening up, fashion shows the diversity of personality.

\section{FASHION AND ITS CURRENT PROBLEMS}

Fashion can be admired and imitated by people as a social fashion in a certain period, which basically reflects the aesthetic tendency of people in a certain period. But in the long course of history, not all current trends are aesthetical beautiful. Sometimes some abnormal things or social behaviors that go against the norm, are disgusting and even violate human nature can even become a fashion and be followed. The emergence of this kind of alternative fashion - current problems is mainly based on the following situations:

\section{A. The fashion phenomenon formed by the deviation or} overcorrection of the public aesthetic consciousness to the cognition of beauty under the specific social ideology

The herd mentality of fashion leads to the blindly following suit of people. In fashion, the usual boundary between beauty and ugliness has almost been erased, and many things that were originally rejected in people's hearts will be easily accepted once they are under the control of fashion. The appearance of current problems in fashion is often the reflection of some abnormal social phenomena in certain historical period. For example, the "three-inch 'golden lotuses' woman's bound feet prevalent in ancient China is a morbid aesthetic developed from the excessive praise 
for the "beauty of small feet", and because it conforms to the patriarchal society's recognition of the "three conformed virtues" of women, this abnormal aesthetic can bind the feet of Chinese women for thousands of years. In the view of modern aesthetic concept, the deformed feet of women created by cruel binding are so ugly. However, as a fashion of that era, the "small, thin, pointed, curved, fragrant, soft and even" small feet were seen as the highest state of foot binding and were followed by all women and became the primary indicator of female aesthetics at that time. For example, during Emperor Daoguang's Reign in the Qing Dynasty, the emperor himself practiced thrift and diligence. As the only emperor who wore patched clothes, civil and military ministers in the court and imperial harem or seraglio followed suit. At a time, it was difficult to find old clothes, and people in the court was proud of wearing patched clothes. They even make patches on their new clothes.

After the reform and opening up, the rapid development of the economy has enabled Chinese people to catch up in the accumulation of wealth and the pursuit of modern fashion. China has been developing at a rapid pace several times faster than the European and American countries, and it only took nearly 30 years to connect with the world. However, there is no lack of immature, deformed or sick fashion concepts in its digestion of modern fashion concepts formed in the West for hundreds of years, resulting in different problems in the fashion of attire. For example, the blind following of fashion causes the chaotic phenomena in people's dress up, and the expansion of wealth and desire contributes to spread of extravagance. These phenomena are inseparable from the complex cultural background of contemporary China. During the Cultural Revolution, the traditional Chinese and Western aesthetics were almost completely denied, replaced by the "proletarian aesthetics" represented by the workers, peasants and soldiers - the unified aesthetic idea advocating sacrificing the individual aesthetics, criticizing and forbidding the instinctive pursuit and desire for beauty as the "bourgeois ideology". After the reform and opening up, mainland China has transformed from a shackled and conservative society to a modern one. In this transition process, economic development as the center replaced the fanatical political movement, people's lifestyle, consumption concept, aesthetic experience and so on have undergone profound changes. With the transformation of social and economic forms and the return of humanism, the original aesthetic view gradually disintegrates. However, the fault in traditional aesthetic culture and the poverty of modern aesthetic consciousness lead Chinese people's aesthetic confusion, and lack of independent thinking about aesthetics and fashion. When Western fashion comes into people's sight with the opening of the country, almost all people regard the fragmented Western fashion as a classic to follow and imitate, and pay more attention to the glossy, bizarre and bustling surface of fashion, without paying attention to the deep social and cultural background of modern Western fashion. The rapid expansion of wealth leads to the extreme expansion of material desire, while the lack of spirit distorts people's view of fashion. Showing off their wealth and consuming fashion has become the best way for some nouveaux riches to show their success, soothe their spirits and fill in their spiritual emptiness. Various fashion luxuries have become their targets, and their ability to spend large sums of money on fashion has blushed the Western society which always has a sense of superiority with shame. However, the fashion concept of the middle class, which can truly represent the mainstream culture of Europe and America, is often ignored or distorted by money-oriented businesses and media, thus creating some extreme phenomena of Chinese people's fashion concept. Although the life style of others can be regarded as fashion and imitated, the culture and taste behind fashion cannot be copied.

\section{B. A peculiar fashion formed by the rebellion of a class or group against the established standards of beauty in society}

For example, the punk group that appeared in the 1970s in the West shocked the world with their deviant and unconventional behavior and their grotesque and sexy appearance. They refuse to accept the traditional value standard, praise highly and yearn for the free way of life, emphasize themselves, pursue novelty and stimulation, and distance themselves from the public with the destructive rebellious consciousness and counter-cultural spirit. In the West, PUNK means bodgie, trash, prostitute, catamite and inferiority, etc. in the dictionary (later the meaning has changed somewhat). The punk costume in the early stage expresses more extreme meaning of sex and violence. What they need is not beauty and classics, but sensory stimulation and instant gratification. This kind of fashion does not take the grade of goods as the coordinates, but attracts people's attention by subverting the traditional aesthetic.

With time passing and the elimination of the false and the true in the course of history, the problems in fashion will eventually be eliminated or evolve into a new form of human nature and social development in line with the human nature and social development which is accepted by the time. Although the current problems has its irrationality, but the history is developing in the unceasing negation. 


\section{MODERN FASHION REPRESENTATION AND TRENDS}

\section{A. The fashion industry and fast fashion}

With the development of the times, Chinese people's fashion concept gradually gets mature and fashion has gradually become a way of life and a state of mind. People's pursuit of fashion is constantly creating new needs and giving birth to new products. In recent years, with the rapid growth of social and economic effects brought by fashion, as well as the continuous emergence and expansion of fashion consumer demand, fashion industry has become a new industry with the greatest development potential. If the origin of fashion based on the mentality of conformity and differentiation of social people at the beginning is a spontaneous behavior, then fashion is gradually replacing a certain idea or a certain belief and becoming a cultural mainstream in modern society. The rise of fast fashion satisfies the endless pursuit of the fastpaced social masses for fashion. Under the constant catalysis of business culture, fashion keeps renovating itself, so that people have a greater choice of space. Meanwhile, behind the fast-changing fashion lies a huge profit driver - business planning, contributing to the symbiotic relationship between consumption and fashion. By constantly making and renovating fashions, merchants obtain greater wealth, and make use of various media to expose people to them, so that individuals can feel the gap in the comparison consciously or unconsciously, and then make up for the emptiness through consumption of fashion and pursue identity in a larger sense. As one Western fashion designer put it: Fashion is planned obsolescence. The speed of fashion renewal is in direct proportion to the speed of wealth depreciation, and a large number of social resources rapidly disappear under the impetus of modern fashion culture, which should arouse people's attention.

Fast fashion is to blame for a large part for the modern obsessive-compulsive disorder and psychological stress. Especially in the contemporary society with a lack of faith, people are often more willing to worship the extravagant material desire for fashion, while ignoring the spiritual expression of fashion. The development of fast fashion is often at the expense of human living environment. While enjoying the satisfaction of modern fashion, people are also experiencing the consequences of a deteriorating environment. Environmental protection and energy conservation have become the world's primary research topics.

\section{B. Sustainable development of fashion}

With the worsening of the living environment, the reflection on the philosophy of life and the concern and thinking of the natural environment are affecting and changing the fashion concept of the world. In recent years, the concept of "sustainable fashion" has been emerging and gradually becoming a trend in Europe and the United States, and has been constantly practiced by designers. For example, Chanel first proposed the concept of Eco Couture in its spring/summer 2016 haute Couture series, and used recyclable and biodegradable materials in its design; since launching its green Conscious line in 2011, H\&M has mostly used sustainable fabrics. At the same time, some social elites begin to reject the modern fashion made by commercial media, turn down luxury and waste, advocate rational consumption, and are keen on social welfare undertakings, so as to feed back their wealth to the society. "Anti-fashion" has become a fashion, which is inevitable for the development of human civilization. From a short-term point of view, its feasibility is questionable, because the spirit of the containment of material desire is not overnight and need a long time of spread and infiltration.

\section{CONCLUSION}

Fashion is not the patent of modern society, but runs through the development of human society in each period, and is subject to the political, economic and cultural constraints of the society. During the spring and Autumn Period, when hundreds of schools of thought were contending and rituals were advocated, Confucianism advocated "restricting self and returning to propriety, being refined in manner" and Taoism advocated "not showing one's talent and letting nature take its course". And in the current commercial era of rampant materialism, fashion is the interpretation of the greediness and extravagance. Thus it can be seen that in a society with spiritual pursuit as the mainstream, fashion pursues noble feelings and often shows temperance, taste and cultivation, while in a society lacking belief and worshiping materialism, people tend to seeking extravagant material desires as fashion, and fashion shows ostentatious, vulgar and extravagant desires. Fashion maximizes people's life needs and aesthetic needs, and promotes the progress of the times in its unique way. However, the pursuit of fashion should not only be based on the guidance and promotion of commercialization, but also needs the support of culture. Blind pursuit of novelty and distinction with endless desire will eventually lead to a new kind of social crisis. However, with the progress of the times and the maturity of fashion culture, energy conservation, environmental protection, and the pursuit of harmony between man and nature will become a new fashion concept for modern people. 


\section{References}

[1] [Germany] Georg Simmel. The Philosophy of Fashion [M]. Trans. by Fei Yong et al. Beijing Culture and Art Publishing House, 2001.

[2] China Fashion Industry Blue Book 2008, CEIBS Fashion Industry Research Center.

[3] Chen Xin. Redemption and Consumption - Consumerism in the Daily Life of Contemporary China. Jiangsu People's Publishing Ltd., 2003.

[4] Wang Yichuan. A New Aesthetic Course. Shanghai: Fudan University Press, 2011

[5] (UK) Dick Hebdige. Subculture: The Meaning of Style. Trans. Lu Daofu, Hu Jiangfeng. Peking University Press, 2011.

[6] Yan Xianglin: On Aesthetic Fashion, Quest, Issue 6, 2017. 